\title{
PANDEMIA E TRABALHO ESCRAVO CONTEMPORÂNEO: REPENSANDO A REINSERÇÃO DO TRABALHADOR RESGATADO A PARTIR DE UMA POLÍTICA EMANCIPATÓRIA
}

\section{RESUMO}

Vitor Hugo Souza Moraes ${ }^{1}$

Cássius Guimarães Chai ${ }^{2}$

Esta pesquisa busca analisar a atuação nacional no combate ao trabalho escravo contemporâneo, situação que assume ainda maior gravidade no contexto da pandemia do COVID-19. Buscou-se focar na propositura de uma metodologia emancipatória de inserção dos trabalhadores resgatados à sociedade. A pesquisa é de revisão bibliográfica e documental com análise de conteúdo e proposições críticas. Conclui-se pela necessidade de pensar o resgate de forma sistêmica, instrumentalizando-o de forma multidimensional para garantir que o trabalhador possa ser adequadamente acolhido e incluído na dinâmica social, de modo a conquistar sua emancipação.

PALAVRAS-CHAVE: Trabalho Escravo Contemporâneo. Ciclo do Trabalho Escravo. Direitos Sociais. Emancipação. Inserção.

\section{PANDEMIC AND CONTEMPORARY SLAVERY: RETHINKING THE REINSERTION OF RESCUED WORKERS FROM AN EMANCIPATORY POLICY}

\begin{abstract}
This research seeks to analyze the national performance in combating contemporary slave labor, a situation that assumes even more seriousness in the context of the COVID-19 pandemic. We sought to focus on proposing an emancipatory methodology for inserting rescued workers into society. The research is a bibliographic and documentary review with content analysis and critical propositions. It concludes by the need to think about the rescue systemically, using it in a multidimensional way to ensure that the worker can be adequately welcomed and included in the social dynamics, in order to achieve his emancipation.
\end{abstract}

KEY WORDS: Contemporary Slave Labor. Slave Labor Cycle. Social rights. Emancipation. Insertion.

\section{INTRODUÇÃO}

\footnotetext{
${ }^{1}$ Advogado (OAB/MA). Mestrando em Direito e Instituições do Sistema de Justiça pela Universidade Federal do Maranhão (PPGDIR-UFMA). Especialista em Direito Público pela Pontifícia Universidade Católica de Minas Gerais (PUC-MG). Graduado em Direito pela Universidade Federal do Maranhão (UFMA).

${ }^{2}$ Doutor em Direito pela Universidade Federal de Minas Gerais (UFMG) e pela Cardozo School of Law-Yeshiva University. Mestre em Direito pela Universidade Federal de Minas Gerais (UFMG). Graduado em Direito pela Universidade Federal do Maranhão (UFMA). Membro do Ministério Público do Estado do Maranhão. Professor Associado da Universidade Federal do Maranhão (UFMA). Coordenador do Grupo de Pesquisa Cultura, Direito e Sociedade
} 
O trabalho escravo consiste na prática, perpetuada no curso da história da humanidade, na submissão de um ser humano a trabalhos forçados ou degradantes, em detrimento do poderio de outro. A mão de obra escrava foi fortemente percebida na Antiguidade Clássica, até ter sido substituída pela servidão no período medieval. Já na Idade Moderna, a expansão ultramarina fez ressurgir fortemente o ciclo da escravidão, que perdurou legalmente por mais 350 anos, embora se perpetue de forma velada até os dias atuais.

No Brasil, país marcado pelo passado de colônia de exploração, a presença de trabalho escravo ocorre desde o início de sua formação. Primeiro tendo como vítima os índios e, depois, os africanos. A escravidão no Brasil durou oficialmente até 13 de maio de 1888, quando a Lei no 3.553 (popularmente conhecida como Lei Áurea) pôs fim a esta prática.

A mazela em questão, por mais que faça referência às práticas coloniais, ainda se faz presente atualmente, assumindo perfil diverso de outrora. Por esta razão, há um intenso debate acerca do que viria a ser a escravidão contemporânea e qual a forma de erradicá-la.

Diante disso, ao longo dos últimos 20 anos, o Estado Brasileiro tem colecionado esforços em busca de combater a exploração de mão de obra, mas, embora já tenham sido libertos mais de 50 mil trabalhadores, pressupõe-se ainda haver outras milhares de pessoas em situações análogas às de escravos.

Contudo, embora o combate efetivo e a libertação dos trabalhadores sejam primordiais e urgentes, a mera garantia da liberdade do sujeito não extingue o seu contexto de miserabilidade. Em verdade, ao encontrar-se livre da situação de trabalho degradante, o trabalhador se vê no mesmo desalento e condição que o possibilitou ser aliciado. Portanto, surge o fenômeno da reincidência do trabalhador à exploração.

No contexto da pandemia enfrentada pelo mundo em 2020, o Brasil inaugura índices preocupantes no tocante ao combate ao trabalho escravo. Aumento do desemprego, aumento da fome e da extrema vulnerabilidade social coloca mais trabalhadores em situação propícia ao aliciamento e exploração. Em sentido igualmente preocupante, o Grupo de Fiscalização está sem fazer fiscalização das denúncias de trabalho escravo contemporâneo.

Destarte, emerge a indagação acerca de como tratar o trabalhador resgatado e, consequentemente, como contornar o quadro de vulnerabilidade social e evitar uma nova redução da pessoa ao trabalho em condições análogas ao de escravo. Assim, o objetivo preponderante desse estudo é analisar o modelo de política pública eficaz para romper o ciclo da vulnerabilidade e garantir uma emancipação efetiva ao trabalhador resgatado. 
Nesse sentido, este estudo se justifica primeiramente ante a relevância social do debate acerca do trabalho escravo - o que implica debater também a inserção do trabalhador resgatado à dinâmica social, como forma indispensável na luta pela erradicação do crime. É de suma importância compreender o que tem sido feito no sentido de prestar assistência às vítimas e quais as lacunas que devem ser supridas.

Para a satisfação dos objetivos do presente trabalho, recorreu-se, em primeira linha, a uma revisão bibliográfica sobre a temática, a modo de formar pleno embasamento sobre a matéria, sobretudo no que tange ao processo de formação do trabalho escravo no Brasil, na conceituação jurídica, nas formas de manifestação do crime e nos métodos de enfrentamento. Já a pesquisa qualitativa deu-se pela análise e interpretação de dados de diversos órgãos e ONGs acerca do enfrentamento. Utilizou-se também de pesquisa de campo para compreender, na prática, o perfil da exploração no estado do Maranhão.

O presente trabalho estrutura-se em três tópicos. Primeiramente, busca-se contextualizar a concepção do trabalho escravo contemporâneo e o combate que é realizado hoje no país. O segundo tópico explica o que é o ciclo da escravidão contemporânea, o qual mantém pessoas na zona de vulnerabilidade e dá fulcro para o objetivo deste estudo. O último tópico discorre sobre a quebra do ciclo da vulnerabilidade, que deve se dar através de uma a reintegração com foco emancipatório do trabalhador por um acolhimento adequado e da inclusão efetiva através de uma política pública conjunta de empresas, Poder Público e sociedade civil, mediante intervenção de políticas públicas amplas e efetivas. Como modelo, apresenta-se a experiência do Movimento Ação Integrada, no estado do Mato Grosso.

\section{O COMBATE AO TRABALHO ESCRAVO CONTEMPORANEO NO BRASIL}

O trabalho escravo contemporâneo não é uma consequência direta da escravização colonial, mas é inegável que se encontra nela raízes sociológicas que a explica. Conforme corrobora o sociólogo Jessé de Souza (2017), a escravidão antiga deixou uma herança de desvalorização do trabalho e negação dos direitos de um grupo em detrimento da manutenção do poderio de outro. "Compreender a escravidão como conceito é muito diferente. É perceber como ela cria uma singularidade excludente e perversa. Uma sociabilidade que tendeu a se perpetuar no tempo, precisamente porque nunca foi efetivamente compreendida nem criticada." (SOUZA, 2017, p. 9). 
Desta forma, infere-se que a perpetuação da mentalidade que subvaloriza a força de trabalho e estabelece a dominação de classes para estruturação social é essencial para a oxigenação das mais diversas formas de exploração.

Dito isto, importante compreender que a exploração de mão de obra, ainda presente de forma expressiva no Brasil, possui perfil variado e nem sempre é facilmente identificável.

Segundo a OIT, o termo "trabalho escravo" funciona como sinônimo de "trabalho forçado", sendo esta toda relação de trabalho que utiliza a coação e privação de liberdade do indivíduo. A Constituição Federal de 1988 traz, em seu artigo 243, o mesmo termo "trabalho escravo", embora não o conceitue.

O termo mais aceito atualmente é o de "condição análoga à de escravo" ou ainda "trabalho escravo contemporâneo" (FIGUEIRA, 2004, p. 42), por entender que "trabalho escravo" remete à escravidão do período colonial, que possuía características distintas da figura atual. Contudo, todas podem ser compreendidas no contexto da exploração no trabalho que ocorre na contemporaneidade, que o conceituado pelo art. 149 do Código Penal Brasileiro, caracterizado pela submissão a "trabalhos forçados ou a jornada exaustiva, quer sujeitando-o a condições degradantes de trabalho, quer restringindo, por qualquer meio, sua locomoção".

Resta fundamental entender que, ao tratar de trabalho escravo contemporâneo não se busca o conceito da exploração colonial, embora haja uma correlação consequencial entre os dois tipos.

Outra terminação que merece zelo para ser evitada é "trabalhador escravo". Durante diálogos com trabalhadores resgatados ${ }^{3}$, percebe-se um incômodo ao referir-se a eles com o adjetivo "escravo". Mais prudente seria "escravizado", já que a condição de escravo não é inata à pessoa, mas sim imposta por um terceiro. O termo mais coerente, portanto, é "trabalhador escravizado".

Vale exemplificar suscintamente, os quatro elementos de tipo que o Código Penal traz para a configuração do trabalho escravo. O primeiro é o trabalho forçado, que ocorre quando o indivíduo é obrigado a exercer mão de obra, seja por ameaça, dívidas, violência física ou psicológica. O segundo é a jornada exaustiva, ou seja, expediente que põe em risco a integridade do trabalhador. O terceiro elemento é a servidão por dívida, caracterizada quando

\footnotetext{
${ }^{3}$ Para a elaboração da presente pesquisa, o autor esteve presente em rodas de conversa com trabalhadores resgatados, no Centro de Defesa da Vida e dos Direitos Humanos Carmen Basrarán, na cidade de AçailândiaMA
} 
são atribuídas cobranças abusivas. O quarto e mais amplo elemento é o das condições degradantes, que pode ser identificado por inúmeras situações precárias às quais o trabalhador pode ser submetido, como maus tratos, alojamento irregular, falta de equipamentos de segurança, ausência de assistência médica ou qualquer outra situação que represente um desrespeito aos direitos fundamentais.

Ademais, acerca do perfil da escravização moderna, o sociólogo José de Souza Martins destaca:

[...] no caso brasileiro, a escravidão (atual) não se manifesta direta e principalmente em más condições de vida ou em salários baixos ou insuficientes. O núcleo dessa relação escravista está na violência em que se baseia, nos mecanismos de coerção moral utilizados por fazendeiros e capatazes para subjugar o trabalhador. [...] Ao analisar a situação fática posta, devemos atentar para a coerção física e moral que cerceia a livre opção e a livre ação do trabalhador, eis que pode haver escravidão mesmo em circunstancia onde o trabalhador não tenha consciência dela. (MARTINS, 1999, p. 127-164).

Quanto ao perfil da vítima do trabalho escravo, quase sua totalidade é do sexo masculino, não-branco ( $81 \%$, segundo o MTE) e com nível de escolaridade muito baixo . Segundo o banco de dados do MTE, a média de idade dos trabalhadores resgatados é de 32,5 anos. São pessoas na faixa da pobreza ou abaixo dela, que não possuíam perspectivas de crescimento profissional e que geralmente possuem dependentes. Os cuidados com o pasto totalizam 50\% dos casos de trabalho escravo no Brasil. Em seguida, vem o desmatamento, com $19 \%$, as atividades ligadas às carvoarias, $12 \%$ e a colheita/plantio, $11 \%$. Outras formas de exploração compreendem $8 \%$.

Ainda assim, algumas ONGs e organizações especializadas estimam os números para dimensionar a ocorrência do crime. O Global Slavery Index (Índice Global da Escravidão) afere que cerca de 45,8 milhões de pessoas estão submetidas à escravização contemporânea no mundo. No Brasil, mais de 161 mil pessoas estariam em condições de escravidão, colocando o país em $51^{\circ}$ lugar da lista de países com trabalho escravo, sendo esta liderada pela Coréia do Norte, Uzbekistão, Cambodia e Índia, respectivamente.

Erradicar a escravização moderna é um processo amplo e complexo, que envolve tempo, planejamento e ações distribuídas de forma sistemática a alguns personagens importantes. A primeira vez que houve um agrupamento dos atores sociais neste sentido foi em 1995, após o reconhecimento da existência de trabalho escravo no Brasil, com a criação do Grupo Executivo de Repressão ao Trabalho Forçado. O grupo reunia sete ministérios, sob a coordenação do Ministério do Trabalho e Emprego (MTE). 
Atualmente, o plano nacional pela erradicação reúne dezenas de instituições como principais atores no combate à exploração humana. Dentre estes, sobressaem-se as responsabilidades do Governo através da articulação de diversos órgãos públicos; a OIT no Brasil; as ONGs, sendo a representação da sociedade civil organizada, a exemplo do Centro de Defesa da Vida e dos Direitos Humanos Cármen Baskarán e a ONG Repórter Brasil; a CPT; os sindicatos e cooperativas de trabalhadores rurais; as Universidades, cujas pesquisas são fundamentais para compreender o problema e embasar as ações, a exemplo do trabalho de pesquisa e extensão desenvolvido pela professora Flávia Moura, da UFMA ${ }^{4}$.

A integração entre esses diversos setores se justifica pelo combate ao trabalho escravo envolver aspectos sociais, econômicos, criminais, políticos, ambientais e trabalhistas, simultaneamente. É, deste modo, indispensável uma abordagem multidimensional.

As atuações delineadas nos planos para erradicação do trabalho escravo subdividemse em 3 áreas: repressão, prevenção e inserção. Tratar-se-á inicialmente dos dois primeiros blocos de ações, deixando o terceiro para ser analisado no último tópico deste trabalho.

A prevenção ao trabalho escravo representa uma forma indispensável de ações quando se trata de enfrentamento ao trabalho escravo contemporâneo. Como já visto, a escravização moderna possui causas histórias, jurídicas, sociais e econômicas que formam uma massa vulnerável à exploração. A prevenção consiste em ações afirmativas para conscientizar as pessoas de seus direitos e garantir que o grupo vulnerável não seja vítima de aliciamento ilegal.

As ações preventivas são promovidas por diversos atores. A exemplo, cita-se a Campanha Nacional de Prevenção do Trabalho Forçado, desenvolvida pela OIT-Brasil a partir de 2003 em parceria com o Governo e a CONATRAE. O projeto consistia em uma massiva divulgação de materiais publicitários pelos meios de comunicação para conscientizar e sensibilizar a população sobre a problemática e foi fundamental para que a opinião pública reconhecesse a existência e gravidade do trabalho escravo e para que os trabalhadores rurais percebessem os riscos do aliciamento, instruindo-os sobre seus direitos e as formas de denúncia. A ação foi vencedora de prêmios publicitários por suas imagens impactantes e pela relevância social.

\footnotetext{
${ }^{4}$ Prof $^{a} \operatorname{Dr}^{\mathrm{a}}$ do departamento de Comunicação Social da Universidade Federal do Maranhão. É pesquisadora da temática Comunicação, Direitos Humanos e Trabalho e participa do Grupo de Pesquisa de Trabalho Escravo Contemporâneo, da UFRJ. Possui publicações sobre a temática, como o livro "Trabalho Escravo e Mídia: Olhares de Trabalhadores Rurais Maranhenses" (2016). Sua pesquisa foi utilizada como referencia bibliográfica para esta pesquisa.
} 
Outro projeto de prevenção de grande relevância é o programa "Escravo, nem pensar!", coordenado pela ONG Repórter Brasil ${ }^{5}$. Nos anos de 2015 e 2016, foi implementado no Maranhão, sendo a primeira vez que era executado com abrangência estadual. O programa estabeleceu uma rede de colaboradores que incluía a Secretaria de Educação e Direitos Humanos do Estado do Maranhão, unidades regionais de educação, escolas estaduais, cientistas sociais e ONGs, como o Centro de Defesa da Vida e dos Direitos Humanos Cármen Baskarán $^{6}$.

O "Escravo, nem pensar!" capacitou professores e lideranças populares do estado e atuou junto aos estudantes da rede estadual do Maranhão. Ao total, foram 203 escolas 62 municípios que receberam o programa, tendo envolvido 131.369 pessoas na campanha de prevenção. Os participantes atuaram, em todas as cidades, de forma ativa junto à sociedade civil, por meio de mostras públicas, passeatas, panfletagem, manifestações teatrais e divulgação de materiais artísticos e informativos, propagando a importância do combate à escravização.

Erradicar qualquer grande mal social perpassa por uma metodologia de prevenção, obviamente. A educação social é fundamental para coibir a existência de todos os tipos de exploração. Entretanto, enquanto são feitas as importantes ações de prevenção, os males sociais, como a escravização contemporânea, continuam a fazer vítimas, afinal, a fome dos vulneráveis não espera.

Dessa forma, tem-se que o setor central no enfrentamento ao trabalho escravo é a repressão, que se dá principalmente pela atuação do Grupo Especial de Fiscalização Móvel (GEFM). O Grupo Especial averigua as denúncias in loco, libertam os trabalhadores explorados e autuam os empregadores rurais. Desde sua criação, mais de 50 mil trabalhadores já foram resgatados pelas fiscalizações, que reúnem auditores fiscais, procuradores do trabalho e policiais federais.

O GEFM fica centralizado na Secretaria de Inspeção do Trabalho, na sede do MTE em Brasília. As denúncias chegam por intermédio da Comissão Pastoral da Terra, pela Polícia

\footnotetext{
${ }^{5}$ ONG fundada em 2001 por jornalistas, cientistas sociais e educadores, com o objetivo de estimular a reflexão e a ação sobre as violações de direitos fundamentais dos povos e trabalhadores do campo no Brasil. Divulga informações, faz reportagens, investigações jornalísticas e pesquisas para serem usadas como instrumentos no combate ao trabalho escravo.

${ }^{6}$ ONG localizada na cidade de Açailândia, criada em 1996, trabalha no combate ao trabalho escravo através de políticas de prevenção no estado, encaminhando denúncias de trabalhadores e executando, de perto, ações de assistência social aos resgatados.
} 
Federal, sindicatos dos trabalhadores e por ONGs como o Centro de Defesa da Vida e dos Direitos Humanos da cidade de Açailândia, no sul do Maranhão. Essas demandas são levadas geralmente por trabalhadores que fugiram do local de exploração ou por aqueles que foram libertados.

Uma vez recebido o pleito, o Grupo de Fiscalização Móvel se organiza pela viabilidade de fazer a averiguação no local da denúncia. Geralmente o grupo aguarda um conjunto de denúncias com fortes indícios do crime em uma mesma localidade para ir fazer a fiscalização nos locais. Então, o Grupo faz uma abordagem no local denunciado, sem aviso prévio, para analisar as condições de trabalho. A partir da análise, pode-se entrar com ações civis, pedidos de execução, restrições a créditos e desapropriação de terras .

Em decorrência da frustração dos jagunços e empregadores com as visitas inesperadas, o Grupo Móvel costuma sofrer riscos, ameaças e ataques violentos para retaliação pela intervenção estatal. Em 2004, por exemplo, a atuação do Grupo em Minas gerais resultou na morte de 3 auditores fiscais e um motorista, ao serem surpreendidos violentamente pelos exploradores que já os esperavam armados.

Apesar das dificuldades, até mesmo relativas à infraestrutura, os números são positivos e repercutem bem a nível mundial, assim como outras ações governamentais a que o Grupo de Fiscalização pode dar início, como a reclamação de seus auditores por indenização aos trabalhadores resgatados referentes às infrações incorridas na fazenda.

A maioria dos empregadores condenados pela utilização de mão de obra escrava são punidos com a imputação ao pagamento de Termos de Ajuste de Conduta, a serem destinados a ONGs e movimentos sociais que defendam os trabalhadores e seus direitos fundamentais. No Maranhão, as 5 operações feitas no ano de 2016, gerou mais de 330 mil reais (MTE, 2017).

Cumpre destacar que a atuação do grupo móvel tem sido minguada por falta de apoio governamental, o que resulta em um decréscimo no número de trabalhadores resgatados. Em 2017, a quantidade de operações do Grupo caiu $25 \%$ e, por consequência, o número de resgatados caiu 23,5\%, segundo dados do Ministério do Trabalho e Emprego. Atualmente, em razão do período de pandemia, as ações do grupo estão paralisadas.

Outra medida, de grande importância, para reprimir neoescravagistas é a divulgação do "Cadastro de empregadores que tenham mantido trabalhadores em condições análogas à de escravo", conhecida popularmente como "Lista Suja". Instituída pela Portaria n ${ }^{\circ}$ 540/2004 do 
MTE, a lista agrupa nomes de empregadores (pessoas físicas ou jurídicas) flagrados na exploração de trabalhadores em situação análoga à escravidão (CHAGAS, 2007, p. 15). Os nomes que a compõem devem ter sido condenados por infrações às leis trabalhistas.

O cadastro é divulgado publicamente pelo MTE e no site da ONG Repórter Brasil, devendo ser atualizada semestralmente. Marco Túlio Viana, da OIT, completa:

\footnotetext{
“Após a inclusão no cadastro, o empregador será monitorado por dois anos. Se durante o período, não houver reincidência do crime, forem pagas todas as multas resultantes da fiscalização e forem quitados todos os débitos trabalhistas e previdenciários, o nome do empregador poderá ser excluído da "lista suja"”. (Viana, 2007, p. 49).
}

Embora a Portaria que cria o Cadastro não implique punições aos empregadores, a inclusão do nome pode representar algumas restrições financeiras. Instituições financeiras como o Banco do Brasil, Banco da Amazônia, Banco do Nordeste e o Banco de Desenvolvimento Social (BNDES) seguem a recomendação do Ministério da Integração Nacional para não conceder créditos e benefícios econômicos aos nomes que constam na "lista suja".

O Cadastro de Empregadores tem sido alvo de grandes ataques no intuito de suspendê-la, sob argumento de ilegalidade. As alegações têm vindo, sobretudo, dos condenados pelo trabalho escravo e políticos financiados por empresas que foram condenadas. Contudo, em 2017 o STF se pronunciou no sentido de manter a divulgação da Lista Suja, por considera-la um legal e importante meio de coibir os criminosos que ocorram no crime. Atualmente a Lista Suja está divulgada através do portal do Ministério do Trabalho.

Especialistas confirmam que a não divulgação da lista é um retrocesso de uma das mais exemplares formas de combate à escravização no contexto mundial. No documento das Nações Unidas de 2016, reforça-se que a reativação do Cadastro de Empregadores pode ser um instrumento de transparência, controle social e propulsor da responsabilidade social empresarial (ONU, 2015).

\section{O GRANDE OBSTÁCULO NA LUTA CONTRA O TRABALHO ESCRAVO: O}

\section{CLICLO DA VULNERABILIDADE}

O resgate, pelo Grupo de Fiscalização, dos trabalhadores explorados não representa o fim do trabalho escravo naquela situação. Em verdade, está longe de sê-lo. O trabalhador recém resgatado, que por hora não é mais explorado, se vê desempregado, sem instrução, endividado, com o psicológico afetado e, muitas vezes, sem contato com os familiares. Acaba, 
por consequência, podendo cair no aliciamento do trabalho escravo novamente, reiniciando o ciclo de exploração.

Durante o período de aliciamento, os trabalhadores são mantidos em locais de difícil acesso, com seus documentos pessoais retidos (OIT, 2010, p. 90) e sem comunicação com seus familiares. As formas de libertação variam, podendo ocorrer quando o empregador abandona o empregado, mediante fuga ou por intermédio do Grupo Móvel de Fiscalização.

No primeiro caso, o serviço para o qual o trabalhador foi aliciado se finda e o empregador o abandona em alguma cidade sem nenhum dinheiro. Sem possibilidade de voltar para sua casa e, muitas vezes, sem contato com sua família, o trabalhador acaba contraindo novas dívidas para sobreviver. Na mesma situação se encaixa aquele que foge do local de trabalho e aqueles que são resgatados por intervenção do Grupo Móvel de Fiscalização e não recebem a devida assistência, voltando a se encaixar no perfil de vulnerabilidade onde estava antes de ser aliciado pela primeira vez.

Em uma situação econômica miserável e contando apenas com a força manual como instrumento de trabalho, o liberto se submete voluntariamente a outras oportunidades de exploração de mão de obra. Surge então um acentuado problema na luta pera erradicação do trabalho escravo: a reincidência.

Segundo dados da Organização Internacional do Trabalho, 60\% dos trabalhadores resgatados é vítima reincidente. A situação foi ratificada pelo Tribunal Superior do Trabalho (TST), que reconheceu a gravidade do problema ao perceber que os nomes de trabalhadores se repetiam em diferentes listas de trabalhadores resgatados.

Ricardo Figueira, sobre a reincidência, comenta:

"Cativos da rede de endividamento progressivo, submetidos a isolamento afetivo,
econômico e geográfico, os trabalhadores entram nesse ciclo que pode ser
considerado uma espécie de suicídio, pois atrela o trabalhador a uma vida sem
perspectivas e abarrotada de humilhações e violências em sucessivas fazendas em
troco apenas de comida" (FIGUEIRA, 2004, p.291).

Outro aspecto relativo ao trabalhador que recém saiu da situação de exploração é o seu estado emocional gravemente abalado. Carregam consigo o sentimento de insucesso e a vergonha sobre as situações a que foram submetidos, que assim como o medo, os impede de falar sobre o ocorrido e, por consequência, de registrar uma denúncia.

Essa situação, que justifica o alto número de reincidência dos trabalhadores às condições análogas à escravidão, institui um vicioso ciclo. Enquanto o trabalhador se 
mantiver na zona de vulnerabilidade, o ciclo tende à repetição, colocando em xeque a efetividade dos esforços empreendidos na repressão e no resgate.

Sob um viés sociológico, SOUZA (2017) analisa que a sociedade brasileira foi forjada à sombra da escravidão e, por isso, uma elite intelectual e econômica constituem a força de reprodução desse sistema. De outro lado, sob sua análise, a classe desfavorecida herda o ódio e a indiferença que antes eram destinados aos escravos, o que pode ser verificado pela ausência de serviços e direitos.

A perpetuação deste sentimento forja um ciclo de exploração que mantém, sempre à margem, aqueles que não fazem parte da elite intelectual e econômica. O patrimonialismo é a base do ciclo.

Em um trecho de sua obra, destaca:

"A colonização da elite brasileira mais mesquinha sobre toda a população só foi
e é ainda possível pelo uso, contra a própria população indefesa, de um racismo
travestido em culturalismo que possibilita a legitimação para todo ataque contra
qualquer governo popular. Todo racismo, inclusive o culturalismo racista
dominante no mundo inteiro, precisa escravizar o oprimido no seu espírito e não
apenas no seu corpo. Colonizar o espírito e as ideias de alguém é o primeiro
passo para controlar seu corpo e seu bolso". (SOUZA, 2017, p. 24 ).

Em análise extensiva, depreende-se que a manutenção de um culturalismo explorador na mentalidade de parte da elite econômica permite que o ciclo de escravidão se perpetue, justificando os altos números de reincidência.

Em paralelo, esta mentalidade pode ser caracterizada como o "poder simbólico" identificado pelo sociólogo francês BOURDIEU (1989), como sendo o poder invisível o qual só pode ser exercido com a cumplicidade daqueles que não querem saber que lhe estão sujeitos ou mesmo que o exercem. Sobre a dominação estrutural, assinala:

É assim que os sistemas simbólicos cumprem a sua função política de instrumentos de imposição ou de legitimação da dominação, que contribuem para assegurar a dominação de uma classe sobre a outra (violência simbólica) dando o reforço da sua própria força às relações de força que as fundamentam e contribuindo assim, segundo a expressão de Weber, para a domesticação dos dominados (BOURDIEU, 1989, p. 11).

Desta forma, o ciclo é embasado, sociológica e antropologicamente pela perpetuação da mentalidade de uma minoria dominante, fato decorrente da herança cultural de uma escravidão mal acabada. Uma vez que esta concepção de uma coletividade se mantém, outro coletivo é subjugado e fica vulnerável aos descaminhos impostos pelo o primeiro grupo. 
Diante do exposto, pode-se concluir que o mero combate isolado é insuficiente para erradicar o problema e que o trabalhador, mesmo que ciente de seus direitos, ainda está sujeito às explorações. Estes dados de reincidência, consideravelmente alarmante, revela que o combate ao trabalho escravo precisa de uma abordagem mais ampla e profunda, preocupandose, também, com a inserção do trabalhador após o resgate. A quebra deste "ciclo da vulnerabilidade", que insiste em reiniciar após a libertação, precisa ser um dos focos do combate à escravização.

Neste sentido de compreender a situação de vulnerabilidade social e econômica que favorece o trabalho escravo, analisar o estado do Maranhão torna-se fundamental. Isto porque atualmente este é o estado que mais "exporta" cidadãos para serem escravizados, em todo o Brasil. Explica-se: de todos os trabalhadores que foram resgatados no Brasil, 22,85\% (mais de 8 mil pessoas) são maranhenses.

Superar este problema implica entender as etapas gradativas às quais o trabalhador deve passar para que não ser mais vulnerável ao crime. A inserção de fato se inicia por um processo de reconstrução da identidade, que deve ser entendida de uma forma subjetiva pelo próprio trabalhador. Na sequência, deve-se fornecer ferramentas adequadas para que ele possa ser socializado no meio em que está inserido.

O processo de inserção do trabalhador, como terceiro pilar do combate à escravização (além da prevenção e combate), deve ser promovido por meio de políticas públicas complexas e eficazes. SECCHI (2013, p. 2), considera política pública "diretriz elaborada para enfrentar um problema público.". Ainda sobre o termo, utiliza-se a compreensão sintetizada por Celina Souza:

Pode-se, então, definir política pública como o campo do conhecimento que busca, ao mesmo tempo, colocar o "governo em ação" e/ou analisar essa ação (variável independente) e, quando necessário, propor mudanças no rumo ou curso dessas ações (variável dependente). A formulação de políticas públicas constitui-se no estágio em que os governos democráticos traduzem seus propósitos e plataformas eleitorais em programas e ações, que produzirão resultados ou mudanças no mundo real (SOUZA, 2007, p. 69).

Acerca do debate acadêmico levantado por SECCHI (2013), se as políticas públicas devem assumir uma abordagem estadista ou multicêntrica, é forçoso concluir que a segunda parece ser mais coerente, visto que o Estado deve assumir um papel preponderante como 
agente na solução de problemas públicos, ainda que alicerçado por setores privados e independentes.

Em uma análise extensiva sobre a situação dos direitos sociais no Brasil e as condições de vida oferecidas aos trabalhadores, é deduzível que, durante a pandemia do COVID-19, a situação dos direitos sociais ficou ainda mais complicada. Recentemente, o Brasil tem tido crescentes índices de desemprego, fome e miséria, ampliando as pessoas vitimadas com a extrema vulnerabilidade social - a porta de entrada para a exploração trabalhista. O ciclo da vulnerabilidade, portanto, fica mais forte nessa atual conjuntura pandêmica.

\section{ROMPENDO O CICLO: EFETIVA INSERÇÃO DO TRABALHADOR RESGATADO E POLÍTICA EMANCIPATÓRIA}

A inserção e assistência à vítima do trabalho escravo foi planejada e prevista no plano nacional pela erradicação. Essa parte dos planos prevê uma série de ações por diversos setores responsáveis com o propósito de repensar a inserção do trabalhador e instrumentalizálo de diversas formas, propondo um modelo de política pública multidimensional para garantir uma efetiva emancipação da vítima do crime, mediante um adequado acolhimento e uma inclusão concreta na sociedade.

Ao participar das fases de acolhimento e inclusão, o trabalhador resgatado deverá construir uma concepção de si próprio como ser social, e se ver dotado de capacidades e direitos. A esta consciência dá-se o nome de emancipação, que pode ser entendida como liberdade, independência e capacidade de autonomia.

Faz-se necessário intercambiar o diálogo sobre a emancipação com outras áreas do conhecimento, como a filosofia e a sociologia. Em uma das clássicas conceituações sobre o tema, Karl Marx demonstra que a emancipação só vem através de uma força centrípeta, ou seja, vinda de fora. É, portanto, uma questão institucional, em que a capacidade emancipatória só é conquistada com o trabalho digno, assegurado pelo setor privado e pelo Estado. Completa ainda o filósofo:

Qualquer emancipação constitui uma restituição do mundo humano e das relações humanas ao próprio homem. A emancipação política é a redução do homem, por um lado, a membro da sociedade civil, indivíduo independente e egoísta e, por outro, cidadão, a pessoa moral. Só será plena a emancipação humana quando o homem real, individual, tiver em si o cidadão abstrato; quando como homem individual, na sua vida empírica, no trabalho e nas suas relações individuais, se tiver tornado um ser genérico, e quando tiver reconhecido e organizado as suas próprias forças como 
forças sociais, de maneira a nunca mais separar de si esta força social como política (MARX e ENGELS, 2006, p. 37).

Em sua obra, Marx divide a emancipação universal em um viés político e outro humano. A emancipação política é quando o indivíduo restitui o poder sobre suas relações, superando os fundamentos econômicos e a alienação política. De outro lado, a emancipação sob viés humano seria, em suas palavras:

Quando o homem individual real tiver recuperado para si o cidadão abstrato e se tornado ente genérico na qualidade de homem individual em sua vida empírica, no seu trabalho individual, nas suas relações individuais, quando o homem tiver reconhecido as suas "forces propres" (forças próprias) como forças sociais e, em consequência, não mais separar de si mesmo a força social na forma de força política. (MARX e ENGELS, 2006, p.54)

Desta forma, obtém-se o entendimento da obra de Marx de que, para obter a emancipação efetiva, o ser humano deve estar em conciliação consigo mesmo, com a natureza e com a comunidade. Deve, portanto, vir sustentada de meios externos e estatais para que cada um alcance a emancipação individual e, em consequência, o coletivo conquiste a emancipação social.

Seguindo nesta ideia, ratifica-se o dever constitucional do Estado garantir o bem estar e a assistência social necessária a manutenção da dignidade do trabalhador. A prestação institucional é fundamental para solidificar a emancipação, sob a concepção marxista.

Não obstante, sob uma perspectiva diferente, a concepção Kantiana entende que a emancipação só é de fato alcançada quando o sujeito assume, subjetivamente, a noção de autonomia. Para tal, Kant destaca a importância da educação para a libertação efetiva do homem. Para alcança-la, portanto, é necessário crer na própria capacidade e na própria dignidade. Frisa-se:

A menoridade é a incapacidade de fazer uso de seu entendimento sem a direção de outro indivíduo. O homem é o próprio culpado dessa minoridade se a causa dela não se encontra na falta de entendimento, mas na falta de decisão e coragem de servir-se de si mesmo sem a direção de outrem. Sapere aude! Tem coragem de fazer uso de teu próprio entendimento, tal é o lema do esclarecimento (KANT, 1974, p.100).

A filosofia kantiana entende, portanto, que a emancipação deve vir "de dentro para fora”, ou seja, através de uma construção psicológica individual de liberdade e autonomia. Esta concepção assegurará que o homem, agora reconhecido por si próprio com sujeito de direitos, não se submeta a exploração que o desqualifique desta qualidade constitucional.

Ainda assim, esta concepção, por perpassar pela educação social e a conscientização de direitos, pressupõe uma atuação estatal forte para torna-la eficaz. Somente com esta prestação o vulnerável poderá compreender seu papel e, então, emergir como senhor de seus próprios direitos. 
O entendimento de emancipação adotado neste trabalho é a união dos conceitos de Marx e de Kant. Trata-se, de forma indissociável, de uma garantia que parte do meio, ou seja, do Estado, sociedade e das relações de trabalho, assim como é o sentimento de autodeterminação adquirido de forma pessoal por cada indivíduo.

A emancipação do trabalhador é, portanto, a essa libertação de si mesmo das amarras que o prendiam à vulnerabilidade do aliciamento. Na medida em que se desenvolvem as capacidades individuais e o exercício da cidadania, o seu papel social é sobressaltado, ficando nítido o seu papel na sociedade, como demonstra Marx no trecho supracitado. Esse processo de libertação nega a dominação humana por compreender a indisponibilidade de direitos como a liberdade e integridade.

Um exemplo de como pode ocorrer esta emancipação foi reconhecida em 2016 pela ONU, ao divulgar que um jovem resgatado do trabalho escravo, e participante do Movimento Ação Integrada de Mato Grosso, havia recuperado a autoestima e ingressado no curso de engenharia na Universidade Federal do Mato Grosso. Reconhece-se, neste caso, a importância do acolhimento e da oportunidade de inclusão para conquistar a sociabilidade e interromper a condição vulnerável.

Este viés emancipatório do processo de inserção é o que garantirá o sucesso das duas fases que serão demonstradas - acolhimento e inclusão. É o objetivo final de todo resgate feito de trabalhadores explorados, instrumentalizando-os com ferramentas para o pleno exercício de seus direitos e cidadania.

A fase de acolhida do trabalhador se dá a partir do momento em que ele sai da situação de exploração, seja por fuga, abandono ou por resgate do Grupo de Fiscalização. Ela é indispensável pois vai determinar a forma como o resgatado enxergará a si mesmo no momento em que ele retorna à sua liberdade. Essa acolhida deve ocorrer sob diversos vieses, como o da cidadania, ao qual cabe a responsabilidade primariamente ao Estado.

Compete ao poder público garantir todos os instrumentos que aos trabalhadores são de direito, mas que, na maioria das vezes, lhes faltam. Cita-se, a exemplo, a carteira de identidade, a carteira de trabalho e o título de eleitor. Garantir o pleno exercício da cidadania é possibilitar ao trabalhador a consciência de sua importância no contexto político, social e econômico do país. É a possibilidade de reconhecer-se como sujeito constitucional ${ }^{7}$.

\footnotetext{
${ }^{7}$ Alegoria utilizada por ROSENFELD (2003) para definir aquele que possui em si a incidência das normas constitucionais. É o sujeito a que a situação se refere, detentor de direitos e garantias. O sujeito, nesse contexto,
} 
Outra alternativa para despertar esta consciência na fase do acolhimento é através de atividades psicopedagógicas que podem ocorrer por atividades em grupo, discussões públicas e a participação dos próprios resgatados nas políticas de erradicação. A exemplo, cita-se a Caravana da Liberdade que ocorre no Maranhão desde 2015, em que os trabalhadores colaboram na organização, nos painéis de discussão e na elaboração de políticas públicas.

O acolhimento é, em resumo, a construção da própria identidade, reconhecendo-se como um ser político, dotado de direitos e potencial de cidadania, através de instrumentos tanto estruturais quanto psicossociais. É, como já dito, indispensável no processo de integração de qualquer indivíduo na sociedade.

De outro lado, a etapa de inclusão é um dos temas mais debatidos em fóruns sobre o trabalho escravo contemporâneo por ser um processo prático e concreto, enquanto o acolhimento depende mais da subjetividade do trabalhador resgatado. Trata-se das condições concretas e objetivas que serão oferecidas aos trabalhadores para que estes ocupem um espaço estável na sociedade.

A inclusão pode se dar pela oferta à educação básica, já que boa parte dos escravizados são analfabetos. Há anos o ensino é mostrado como um instrumento de base para o exercício da independência, do protagonismo social e do exercício de direitos. É a principal ferramenta propulsora do exercício cidadão. O pedagogo Paulo Freire reafirma:

"Busca de uma educação séria, rigorosa, democrática, em nada discriminadora
nem dos renegados nem dos favorecidos. Isso, porém, não significa uma prática
neutra, mas desveladora das verdades, desocultadora, iluminadora das tramas
sociais e históricas. Uma prática fundamentalmente justa e ética contra a
exploração dos homens e das mulheres e em favor de sua vocação de ser mais"
(FREIRE, 2001, p. 30).

Os marcos legais brasileiros relativos à educação já trazem a legitimação dessa prática como forma fundamental de participação social. O artigo 250 da Constituição da República entende que "a educação, direito de todos e dever do Estado e da família, será promovida e incentivada com a colaboração da sociedade, visando ao pleno desenvolvimento da pessoa, seu preparo para o exercício da cidadania e sua qualificação para o trabalho". De outro lado, a Lei de Diretrizes e Bases para a Educação Brasileira de 1996, no seu primeiro artigo, prevê:

apresenta dois sentidos conexos e consequenciais: primeiro, o sujeito que se submete ao Estado de Direito, que está sujeito às normas constitucionais. Em consequência do primeiro, surge o segundo sentido, no qual apresenta-se a emersão do sujeito enquanto detentor e possuidor de direitos, ou seja, um sujeito de direitos. No contexto do presente trabalho, entende-se que o trabalhador, uma vez submetido ao Estado, possui capacidade para emergir enquanto sujeito de direitos constitucionais, dentre eles, os direitos sociais. 
"A educação abrange os processos formativos que se desenvolvem na vida familiar, na convivência humana, no trabalho, nas instituições de ensino e pesquisa, nos movimentos sociais e organizações da sociedade civil e nas manifestações culturais". (BRASIL, 1996).

Diante do amparo legal e do entendimento de Paulo Freire sobre a importância da educação popular nesse processo de inclusão, identificada como "prática de liberdade garantidora de um futuro autônomo para aqueles que constituem o objeto de sua ação" (FREIRE, 1992, p. 23), entende-se que este deve ser uma etapa fundamental para a inclusão do trabalhador resgatado.

Ao analisar-se as ações no Brasil que buscam a erradicação do trabalho escravo, conclui-se que o método mais eficaz é um trabalho multidisciplinar que envolva o correto acolhimento e a efetiva inclusão do trabalhador, de modo a que ele se emancipe da condição de vulnerável e saia da zona de risco do aliciamento.

Tomando esta concepção como ponto de partida, tem-se um amplo projeto de emancipação, denominado de Movimento-Qualificação Ação Integrada, lançado no estado de Mato Grosso em 2009. Tamanho o sucesso do projeto, já se expandiu aos estados do Pará e Rio de Janeiro, com perspectivas para ser levado a outros estados.

O Movimento Ação Integrada, como é conhecido, congrega organismos governamentais e privados para promover uma modificação social, educacional e econômica dos resgatados da neoescravização, rompendo com a condição vulnerável que mantém o ciclo do trabalho escravo.

A emancipação a que se busca para quebrar o ciclo da vulnerabilidade é aquela em que o trabalhador se percebe como sujeito de direito e garantias, afastando as possibilidades de ter sua mão de obra subvalorizada por qualquer aliciador. Há uma necessidade latente, sobretudo no campo do país, em projetos com este viés, a exemplo do Movimento que aqui fora exposto.

\section{CONSIDERAÇÕES FINAIS}

O estudo sobre trabalho escravo contemporâneo no Brasil é matéria de suma relevância, dada a insistente perpetuação desta problemática ao longo dos anos, mesmo que contrária aos diplomas legais vigentes. Na busca pela compreensão das novas formas de escravização moderna e de uma metodologia para a inserção do trabalhador resgatado à sociedade, como forma de combate ao crime, o presente trabalho buscou entender as bases 
que sustentam a exploração e conceber sob qual viés deve se basear a luta pela sua erradicação.

Portanto, conforme já suscitado, a temática em questão assume grande importância a partir do momento em que a inserção do trabalhador resgatado é medida de combate ao trabalho escravo. Logo, o desenvolvimento de uma política pública, em que atuem diversos setores, com o fim de combater o trabalho escravo contemporâneo, não pode ser pormenorizado, se comparado com as outras etapas de combate - prevenção e combate. Isso porque é incontestável a situação de vulnerabilidade em que vive a vítima de trabalho análogo ao de escravo, carecendo, assim, de amparo imediato, a fim de evitar sua reincidência na situação de trabalhador escravizado.

No Brasil, temos a base de combate ao trabalho escravo contemporâneo por preceitos positivados pela Constituição da República. A Carta Maior consagrou a valorização social ao trabalho no bojo do seu artigo $1^{\circ}$, IV. Logo, compreende-se que é papel do Estado assegurar os direitos aos trabalhadores previstos legalmente, vistos que tais garantias estão previstas na própria Constituição. Nesse diapasão, a exploração ao trabalho análogo ao de escravo é prática que viola a proteção ao trabalhador, assim como sua própria dignidade.

Posto isso, quanto a caracterização do trabalho escravo contemporâneo, tem-se que a exploração se apresenta hoje de diversas formas, destacando-se a atividade rural, têxtil e na construção civil.

O enfrentamento ao Trabalho Escravo Contemporâneo é organizado pelo plano nacional pela erradicação, que organizam ações de prevenção e combate ao trabalho escravo e as distribuem entre diversos setores da sociedade, como governo, ministério público, defensoria pública, ONGs e setor privado.

A prevenção é etapa essencial ao combate ao trabalho escravo, por atingir a base de todo o processo: educação e conscientização. De outro lado, enquanto a prevenção trabalha na raiz do problema, o combate efetivo propõe-se a coibir o crime e punir os infratores. Entre as ações, destaca-se a atuação do Grupo Especial Móvel de Fiscalização, que faz as averiguações das denúncias por trabalho escravo in loco, para libertar os trabalhadores que estiverem em situação de exploração. O atual desafio do Grupo Móvel é se manter atuante apesar dos sucessivos cortes orçamentários que têm dificultado as fiscalizações, e suspensão dos trabalhos em razão da pandemia. 
Apesar de tudo, o que se percebe é que o enfrentamento efetivo ao trabalho escravo necessita de uma visão ampla do processo completo. O trabalhador que é resgatado, ou que foge do local de exploração, geralmente não possui quaisquer condições de ser inserido na sociedade e, por vezes, é novamente explorado por outros empregadores.

Este ciclo dá-se por diversas razões, como da perpetuação de um poder simbólico que subjuga uma classe e a escraviza por desconsiderar seus direitos constituídos. De outro lado, é a consequência direta do pensamento escravocrata e de desvalorização do trabalho que permeia a mente de parte da elite brasileira. Na prática, isso tudo ocasiona uma repetição de vulnerabilidade que prejudica todo o combate ao trabalho escravo.

No intuito de romper este ciclo e garantir os direitos do trabalhador que foi resgatado, propõe-se uma metodologia de política pública com um viés emancipatório. Ou seja, o processo pós resgate precisa garantir ao trabalhador o reconhecimento de sua qualidade de sujeito possuidor de direitos e o instrumentalize de diversas formas a fim de garantir que ele não pertença mais à condição de vulnerável e, assim, que rompa com a perpetuação da escravização.

Dentre as ações emancipatórias que efetivarão a inserção do trabalhador na sociedade, destaca-se o acolhimento a ser feito a partir do momento do resgate. Deverão ser garantidos todos os benefícios sociais a que se tem direito, como o seguro-desemprego, todos os documentos civis e uma assistência que o ajude a estabilizar sua vida através da compreensão de todos os seus direitos e garantias legais. Neste aspecto, é fundamental a presença do Estado, das ONGs e das Universidades para trabalhar no processo.

De outro lado, ações de inclusão são fundamentais para concluir o processo de emancipação. Através da educação e da profissionalização, o trabalhador passará a possuir condições concretas de adquirir condições dignas de sustento e não necessitará mais submeter-se às condições degradantes para sobreviver.

Toda esta metodologia foi empregada em uma política pública de grande êxito no Mato Grosso: o Movimento Ação Integrada, que já beneficiou milhares de pessoas através da parceria do governo, do Sistema S, da Universidade Federal e empresas privadas.

Assim, deve-se aproveitar os instrumentos que já existem e agregá-los a uma política multidimensional e emancipatória, que garanta que os trabalhadores possam romper o ciclo da vulnerabilidade e não se submetam mais ao trabalho escravo contemporâneo. Esse tratamento, através de um processo a longo prazo, traduzirá um passo fundamental para a erradicação do 
trabalho escravo no Brasil e garantirá a efetividade de todas as ações de prevenção e combate já existentes.

\section{REFERÊNCIAS BIBLIOGRÁFICAS}

BOURDIEU, Pierre. O poder simbólico. Tradução Fernando Tomaz. Lisboa: Difel, 1989 BRASIL.

BRASIL, Repórter. Escravo, nem pensar! No Maranhão 2015/2016. Produção Independente, 2016. Disponível em <http://escravonempensar.org.br/wpcontent/uploads/2017/04/caderno_resultados_enp-ma_baixa.pdf.> Acesso em: 27/09/2020.

. Empresas Flagradas com Trabalho Escravo Contemporâneo financiaram 10

dos deputados federais. Disponivel em http://reporterbrasil.org.br/2018/01/empresasflagradas-com-trabalho-escravo-financiaram-10-dos-deputados-federais/. Acesso em: 04/06/2019.

CHAGAS, Daniel de Matos Sampaio. O Ministério do Trabalho e Emprego e os Subsídios para Defesa Judicial da União nas Ações Relativas ao Cadastro de Empregadores do Trabalho Escravo. In. Possibilidades Jurídicas de Combate à Escravidão Contemporânea, Brasília: OIT, 2007.

COETRAE/MA. II Plano Estadual para Erradicação do Trabalho Escravo no Maranhão. Disponível em: <coetraes.reporterbrasil.org.br/wpcontent/uploads/2014/08/Plano-Estadual-MA.pdf>. Acesso em 28/09/2020.

COMISSÃO INTERAMERICANA DE DIREITOS HUMANOS. RELATÓRIO No 95/03 CASO 11.289 - JOSÉ PEREIRA. Disponível em: < https://cidh.oas.org/annualrep/2003port/Brasil.11289.htm>.

Convenção Interamericana de Direitos Humanos. Costa Rica, 1969.

Disponível em <http://www.cidh.oas.org/basicos/portugues/c.convencao_americana.htm>. Acesso 10/04/2018.

FARIA, Regina Helena Martins de. Mundos do trabalho no Maranhão oitocentista: os descaminhos da liberdade. São Luís: Edufma, 2012.

FIGUEIRA, Ricardo Rezende. Pisando Fora da Própria Sombra: A escravidão por dívida no Brasil contemporâneo. Rio de Janeiro: Civilização Brasileira, 2004.

FREIRE, Paulo. Política e educação. 5a ed. São Paulo: Cortez, 2001.

. Pedagogia da Esperança. São Paulo: Paz e Terra, 1992.

GOLD, STEFAN AND TRAUTRIMS, Alexander and Trodd, Zoe (2015) Modern slavery challenges to supply chain management. Supply Chain Management, 20. pp. 485-494.

KANT, Immanuel. Resposta à pergunta: que é esclarecimento?. In: KANT, Immanuel. Textos seletos. Petrópolis: Vozes, 1974. p.101 -117.

LIGA DAS NAÇÕES. Convenção sobre a Escravatura. Genebra, 25 de setembro de 1926. Disponível em $\quad<\quad \mathrm{http}: / / \mathrm{p}$ fdc.pgr.mpf.mp.br/atuacao-e-conteudos-deapoio/legislacao/trabalho-escravo/convencao_escravatura_genebra_1926.pdf/>.

MARTINS, José de Souza. Fronteira: a degradação do outro nos confins do humano. São Paulo: Hucitec, 1997. 
MARX, K e ENGELS, F. A Questão Judaica.In: Manuscritos Econômico-Filosóficos. São Paulo: Martin Claret, 2006.

MOURA, Flávia de Almeida. Trabalho escravo e mídia: olhares de trabalhadores rurais maranhenses. São Luís: EDUFMA, 2016.

. Escravos da precisão: economia familiar e estratégias de sobrevivência de

trabalhadores rurais em Codó (MA). São Luís: Edufma, 2009.

MTE. Resultados das operações de fiscalização para erradicação do trabalho escravo. Disponível em: 〈http://trabalho.gov.br/dados-abertos/estatistica-trabalho-escravo>. Acesso em 19/02/2019.

ORGANIZAÇÃO INTERNACIONAL DO TRABALHO. Combatendo o Trabalho Escravo Contemporâneo: o exemplo do Brasil. Brasília: OIT, 2010.

ORGANIZAÇÃO DAS NAÇOES UNIDAS. Declaração Universal dos Direitos Humanos. Disponível em: 29/09/2020

PIOVESAN, Flávia. Trabalho escravo e degradante como forma de violação aos direitos humanos. In: VELLOSO, Gabriel; FAVA, Marcos NEVES (coord.). Trabalho Escravo Contemporâneo: o desafio de superar a negação. São Paulo: LTr, 2006.

ROSENFELD, Michel. A identidade do sujeito constitucional. trad. Menelick de Carvalho Netto. Belo Horizonte: Mandamentos, 2003.

SECCHI, Leonardo. Políticas públicas: conceitos, esquemas de análise, casos prático. 4. ed. São Paulo: Cengage Learning, 2013.

SOUZA, Jessé. A construção social da subcidadania: para uma sociologia política da modernidade periférica. Belo Horizonte: Editora UFMG; Rio de Janeiro: IUPERJ, 2003.

. A elite do atraso: da escravidão à lava jato. São Paulo: Ed. LeYa, 2017.

VIANA, Marco Túlio. Trabalho Escravo e "Lista Suja": um modo original de remover uma mancha. In, Possibilidades Jurídicas de Combate à Escravidão Contemporânea, Brasília: OIT, 2007.

VIEIRA, Oscar Vilhena. A desigualdade e a subversão do Estado de Direito. P. 191 216. Rio de Janeiro: Lumen Juris, 2008. 